\title{
Laparoscopy for evaluation of infertility patients in a tertiary center in north-eastern Nigeria
}

\author{
Muhammad B. Aminu, Lamaran M. Datttijo, Saidu A. Kadas, Abubakar M. Shehu, \\ Calvin M. Chama \\ Department of Obstetrics and Gynecology, Abubakar Tafawa Balewa University Teaching Hospital, Bauchi, \\ Nigeria
}

\begin{abstract}
Laparoscopy uses fiber optic endoscope passed through the abdominal wall to visualize the peritoneal cavity for both diagnosis and therapy; it is also referred to as Minimal Access Surgery. It is an important tool in the evaluation of infertility. The objective of this study is to determine the value of laparoscopy for evaluation and treatment of infertility patients in Bauchi. North east, Nigeria. This is a retrospective cross-sectional study of women who had evaluation using laparoscopy. The case files and theatre records of all the women who had laparoscopy over a 5 -year period between the 21st February, 2012 and 20th January, 2017 were retrieved and analyzed. Data on age, parity, type of infertility, intra operative findings and type of procedures done were extracted using a proforma. Analysis was done using statistical package for social sciences (SPSS version 21, IBM). One hundred and thirty-seven women had laparoscopy and or hysteroscopy during the review period, retrieval rate was $98 \%$. Mean age was 29 years \pm SD. Median number of pregnancies was 2. Most of the women had laparoscopy for secondary infertility indicated by tubal or an ovarian factor. Thirty-two (32) women $(23.4 \%)$ had normal study. Sixteen (16) interventional procedures $(12 \%)$ were done during the study period ranging from ovarian cystectomy, adhesiolysis, salpingectomy and sterilization. There were nine (9) congenital abnor-
\end{abstract}

Correspondence: Muhammad Baffah Aminu, Department of Obstetrics and Gynecology, Abubakar Tafawa Balewa University Teaching Hospital, Bauchi, Nigeria.

Tel.: +2347037147717

E-mail: aminubaffahmuhammad@gmail.com

Key words: Video laparoscopy, infertility, hysteroscopy, intervention.

Contributions: the authors contributed equally.

Conflict of interest: the authors declare no potential conflict of interest.

Funding: none.

Received for publication: 30 April 2018.

Revision received: 15 Otober 2018.

Accepted for publication: 18 Otober 2018.

This work is licensed under a Creative Commons Attribution NonCommercial 4.0 License (CC BY-NC 4.0).

(C) Copyright M.B. Aminu et al., 2018

Licensee PAGEPress, Italy

Annals of African Medical Research 2018; $1: 9$

doi:10.4081/aamr.2018.9 malities detected during the period. Fifteen (15) women had both hysteroscopy and laparoscopy. Three women (2.8\%) had uterine perforation with only one converted to laparotomy giving an overall success of $97 \%$. Laparoscopy has changed the perception of many gynecologists in the diagnosis and treatment of infertility from mere imaginative to definitive thoughts.

\section{Introduction}

One of the most important tools used over the years in the diagnosis and now the treatment of most gynecological problems is laparoscopy whose existence dates back to the turn of the 19th century when Kurt Semm initiated the concept of operative endoscopy. ${ }^{1}$

Laparoscopy has now become a common tool in the evaluation of patients in the field of gynecology for some decades following its introduction even in developing countries. ${ }^{2,3}$ About half a million $(400,000)$ hysterectomies done in the United Kingdom ${ }^{4}$ is via laparoscopy, and more than $50 \%$ of gynecology residents in Canada are at ease performing a laparoscopic hysterectomy. ${ }^{5}$ This procedure has also been made a household name in most elective surgeries in the developed world mainly due to the lower risk of complication which is less than $10 \%{ }^{6}$ Across Africa, published articles from Ethiopia and Kenya indicated the usefulness of the technique. ${ }^{7,8}$ In Nigeria, tertiary hospitals had reported on laparoscopy. ${ }^{9}$ In the year 2009, 58 cases were reported over a 4year period from the National Hospital, Abuja with infertility as the commonest reason for the procedure. Across all the centers in the country, tubal factor infertility accounts for about $30 \%$ of all the causes of infertility. ${ }^{10}$ While the developed world is advancing in minimal access surgery for oncologic patients, the developing countries are faced with the challenges of resources, expertise and cost. ${ }^{11,12}$ In the South east and North western, Nigeria experiences with laparoscopy has been reported illustrating its usefulness in gynecological practice. Before now, nearly all gynecological operations are done via a wide incision that could either be midline or Pfannenstiel. The advent of laparoscopy has breached this gap; it has brought innovation and pride to the practice of gynecology worldwide. Laparoscopy since its advent has offered the advantages of improved diagnosis and treatment, short hospital stays, ${ }^{2.3}$ less bleeding, early return to work and above all the involvement of every theatre user including learning benefit for medical students and residents.

Laparoscopy is considered the gold standard in the diagnosis of infertility, ${ }^{13}$ taking over the conventional Hysterosalpingography (HSG) with the added advantage of providing detail information on the anatomic changes that result in infertility. The therapeutic values of this procedure cannot be underestimated as many laparoscopic interventions have resulted in pregnancy for the infertile couple. 
This study aimed to determine the value of laparoscopy for women that were evaluated and managed for different gynecological conditions at the Abubakar Tafawa Balewa University Teaching Hospital (ATBUTH) Bauchi over a 5-year period.

\section{Materials and Methods}

The study was a retrospective cross-sectional study of all the cases that had laparoscopy with or without hysteroscopy done in the Department of Obstetrics and Gynecology, Abubakar Tafawa Balewa University Teaching Hospital, Bauchi - Nigeria from February, 2012 to January, 2017. Theatre records as well as case notes of the patients were retrieved and relevant information were obtained which included, age, parity, place of residence, type of infertility, type of procedure (laparoscopy and or hysteroscopy), indication for the procedure, findings at laparoscopy, duration of procedure, entry point and complications encountered. Ethical approval was sought and obtained from the research and ethics committee of the ATBUTH, Bauchi. Cases in which the bio-data or other clinical and laparoscopic findings were missing were excluded from the study. The data was retrieved and analyzed using SPSS version 21 . The results were presented below.

\section{Results}

A total of 137 patients who had laparoscopy and/or hysteroscopy from February, 2012 to January, 2017 for various indications were reviewed. The mean age of the patients was 27 years (SD). Women of age less than 20 years constitute the majority of the patients evaluated during the study accounting for about $60 \%$ (82) of the population, with only 4 (3\%) from women between the ages of 31 to 40 . Women of low parity, 0 to 2 were the largest group that were evaluated for infertility $89 \%$ (112) during the review period as shown in Table 1 .

Among the age groups, age less than 20 had the highest number of normal studies with 21 out of $32(65.6 \%)$ patients whose study revealed no abnormality. Hydro salpinx of one or both tubes was seen in $16(12 \%)$ of women, other findings are shown in Figure 1 and Table 2.

A total of 49 completely blocked tubes were discovered during the period with none in the advanced age group 41 and above. There was only one conversion to open surgery during the review period.

\section{Discussions}

A total 137 patients were studied. Mean age of the population studied was 26.71 years (Range 18-41years), this is in deviant from a study done in the South -south and North central, Nigeria where the mean ages were 27.3 and 32.1 years respectively, 3,10 it is not uncommon with women from northern Nigeria who tend to embark on child bearing earlier than their counterparts from the other regions of the country. Most of the patients $82(59.9 \%)$ were in age group less than 20years many of whom had normal laparoscopic findings (Table 1). Out of the 128 patients investigated for infertility, 49(36\%) patients had primary infertility and $79(58 \%)$ had secondary infertility (Table 2 ). Findings from this study indicated secondary infertility as the commonest indication for performing laparoscopy with frequency of $79(58 \%)$; this is similar to that noted in the study in Sokoto, Kano North West, Nigeria and by
Agrawal et al. in 2018, ${ }^{14-16}$ largely due to the similarity in cultures in the first two regions. But in contrast to findings reported from the South east, Nigeria and in India were primary infertility was the commonest indication for laparoscopy. ${ }^{17,18}$

The median parity of the studied population was one (1) with nulliparae also constituting the majority 73 (53.3\%). This finding correlates with the studies from South east, Nigeria where the median parity was also one and that from a study in Iran with nulliparae also constitute the majority among the clients evaluat-

Table 1. Sociodemographic characteristics of 137 women evaluated for infertility.

\begin{tabular}{lccc} 
Frequency & Percent & $\begin{array}{c}\text { Cumulative } \\
\text { Percent \% }\end{array}$ \\
Age, years & & & \\
Less than 20 & 82 & 60 & 60 \\
$21-30$ & 51 & 37 & 97 \\
$31-40$ & 4 & 3 & 100 \\
Total & 137 & 100 & \\
Parity & & & \\
0 & 73 & 53 & 53 \\
1 & 20 & 15 & 68 \\
2 & 29 & 21 & 89 \\
3 & 13 & 10 & 99 \\
4 & 1 & 1 & 99 \\
6 & 1 & 1 & 99 \\
Total & 137 & 100 & \\
\hline
\end{tabular}

Table 2. Frequency distribution of type of infertility, laparoscopic findings and interventions among clients.

\begin{tabular}{lccc} 
& Frequency & Percent & $\begin{array}{c}\text { Cumulative } \\
\text { Percent \% }\end{array}$ \\
Infertility & & & \\
$\quad$ Primary & 49 & 36 & 38 \\
Secondary & 79 & 58 & 100 \\
$\quad$ Total & 128 & 93 & \\
Laparoscopic findings & & & \\
Tubal blockage & 18 & 13 & 6 \\
Pelvic adhesion & 46 & 34 & 100 \\
Uterine Myoma & 23 & 16 & \\
Ovarian cyst & 10 & 7 & \\
Hydrosalpinx & 16 & 12 & \\
PCOs & 18 & 13 & \\
Endometriosis & 3 & 2 & \\
\hline
\end{tabular}

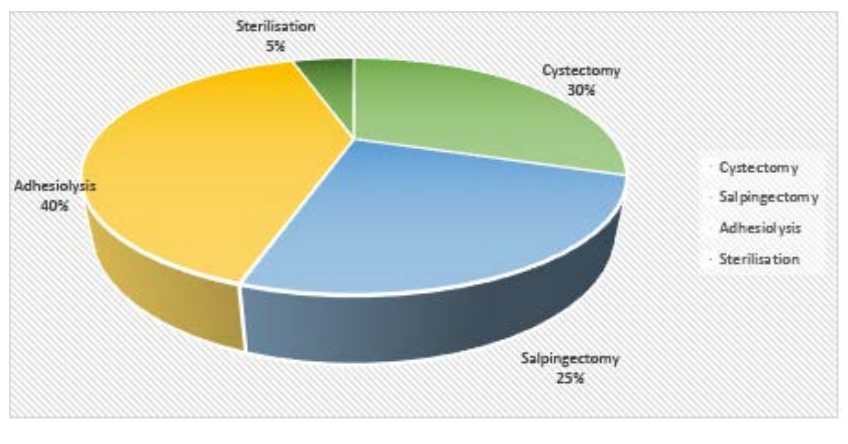

Figure 1. Distribution of laparoscopic interventions in 20 patients. 
ed. ${ }^{19,20}$ This shows that patients presenting for evaluation usually have fewer children hence the need for infertility evaluation in a culture that places high premium on childbearing.

The majority of our women evaluated during the study period were less than 20 years and this could be attributed to the culture of early marriage and childbearing in the study area. This is in contrast to the findings noted in studies conducted by other workers ${ }^{13}$ and in the South-east where age range of 21 to 46 years was noted. ${ }^{19}$ Similarly, the high number of low parity women observed could be attributed to the high premium the culture has for childbearing and for male children in particular.

Our study revealed that endometriosis may not be so common in our study population as it was observed in only $3(2.2 \%)$ of cases. This is lower than figures from the South-east and Southwest of Nigeria; ${ }^{21}(4.9 \%)$ and (20\%) respectively, ${ }^{22}$ and amongst Asians, ${ }^{23}$ but all these figures are inconsistent with the global figure of $8-10 \% .^{24}$

The incidence of normal sized uterus and ovaries noted in our study is $23.4 \%$. This is in contrast to the study by Garima et al. in India which reported the incidence of $49.29 \%$, ours may be attributed to the number of patients studied which was about half of the Indian study. ${ }^{13}$

The incidence of polycystic ovaries observed in our study was $13 \%$ (Table 2), a rate lower than the one reported from south-east Nigeria $^{19}$ and from Egypt where a rate of $25.1 \%$ was reported, ${ }^{25}$ this was even commoner among women with normal and blocked tube. Our bilateral tubal block was discovered to be $13 \%$, similar to the study by Tanaka et al., where more than $50 \%$ of the study participants had both tubes blocked. ${ }^{26}$ This finding is in sharp contrast to an Indian study by Garima et al where the incidence was $23.26 \%,{ }^{13}$ in the same vein, a study in Nigeria indicated a bilateral tubal block in $20 \%$ of the studied population. ${ }^{19}$

As sequelae to pelvic infection, sixteen women 16 (12\%) from the study population had hydro salpinx, $4.4 \%$ each on the right and left tube and $2.9 \%$ on both tubes, ${ }^{6}$ this may not be so surprising due to the early sexual debut and multiple sexual partners from polygamy. Higher figures of $41.1 \%$ and $20 \%$ have also been quoted respectively for hydro salpinx and bilateral tubal blockage from a Nigerian study in 2017. ${ }^{19}$ Tubal blockage and hydro salpinges are relatively common findings in sub-Saharan Africa and globally due to high prevalence of pelvic infections. ${ }^{27}$

The study further buttresses the role of myoma as a possible reason for sub-fertility with $18(13.1 \%)$ of all the clients that had fibroids during evaluation having abnormal tubes. ${ }^{28-30}$

Some of the weaknesses of the study include its retrospective nature and was done at a tertiary hospital hence may affect the generalization of findings. Similarly, outcome of the procedure and interventions could not be obtained due to the nature of the study hence the need for a prospective follow up of the patients.

\section{Conclusions}

This study further confirms the important role laparoscopy play in the evaluation and treatment of infertility patients. Valuable information can be obtained from the use of laparoscopy and further capacity building in these procedures will improve care of patients with infertility in our environment.

\section{References}

1. Mettler L. The evolution of gynaecologic endoscopic surgery over 50 years-a rocky road. Med Res Arch 2017;15:5.

2. Akintobi AO, Bello O, Asaolu OA, et al. Laparoscopic supracervical hysterectomy and uterine morcellation: A case report from Asokoro District Hospital, Abuja, Nigeria. Nig J Clin Pract 2015;18:824-7.

3. Omokanye LO, Olatinwo AW, Ibrahim S, et al. Gynecological laparoscopic surgeries: A 4-year audit at the University of Ilorin Teaching Hospital, Nigeria. Trop J Obstet Gynecol 2017;34:49.

4. Worldwide AA. AAGL practice report: morcellation during uterine tissue extraction. J Minim Invasive Gynecol 2014;21: 517-30.

5. Sanaee M, Sobel M. O-GYN-MD-112 Canadian Obstetrics and Gynaecology Residents: Are They Ready for Independent Practice? J Obstet Gynaecol Canada 2017;39:400-1.

6. Sutton C. A practical approach to surgical laparoscopy. In: Sutton C, Drummond PM, eds. Endoscopic Surgery for Gynaecologists. 2nd ed. London: WB Saunders; 1998. p. 4153.

7. Esayas R, Shumey A, Selassie KG. Laparoscopic surgery in a Governmental Teaching Hospital: An initial experience from Ayder Referral Hospital in Northern Ethiopia. East Central Afr J Surg 2015;20:49-54.

8. Makin J, Ramanathan A, Parkar R, et al. Cost of Gynecologic Laparoscopy in Rural Western Kenya [21D]. Obstet Gynaecol 2017; 129:47S.

9. Famurewa O, Adeyemi A, Ibitoye O, Ogunsemoyin O. Association between history of abdominopelvic surgery and tubal pathology. Afr Health Sci 2013;13:441-6.

10. Clever O, Esther A, Ebuka O, Anthony M. Relative assessment of abnormalities patterns in hysterosalpingography, diagnostic laparoscopy and hysteroscopy with infertility cases in women in Nigeria. Int J Obstet Gynecol 2015;3:81-9.

11. Schwartz M, Jeng CJ, Chuang LT. Laparoscopic surgery for gynecologic cancer in low-and middle-income countries (LMICs): An area of need. Gynecol Oncol Rep 2017;20:1002.

12. Alfa-Wali M, Osaghae S. Practice, training and safety of laparoscopic surgery in low and middle-income countries. World J Gastrointest Surg 2017;9:13.

13. Padmawar A, Arora GG. Causes of infertility with reference to laparoscopic findings. Small 2016;11:5-31.

14. Nasir S, Hassan M, Tunau K, et al. Experience with gynaecological laparoscopy in a tertiary hospital, North-West Nigeria. Orient J Med 2014;26:48-52.

15. Yakasai IA, Abdullahi J, Omole-Ohonsi A, Ibrahim SA. Gynaecologic Laparoscopy at Aminu Kano Teaching Hospital, Kano, Nigeria: A 5-year review. Br J Sci 2012;5:11-7.

16. Agrawal N, Fayyaz S. Can hysterolaparoscopic mediated chromopertubation obviate the need for hysterosalpingography for proximal tubal blockage? An experience at a single tertiary care center. J Gynecol Obstet Human Reprod 2018.

17. Ikechebelu J I. Experience with diagnostic laparoscopy for gynaecological indications. Niger J Clin Pract 2013;16:155-8.

18. Chaudhari AD, Baria AM, Chaudhari UR, et al. Diagnostic laparoscopy in the evaluation of tubal factor in cases of infertility. Int J Reprod Contracept Obstet Gynecol 2017;6:1275-8.

19. Ugboaja JO, Oguejiofor CB, Ogelle OM. Tuboperitoneal anomalies among infertile women in Nigeria as seen on laparoscopy. Int J Gynecol Obstet 2017.

20. Akhtar R, Taj N, Mehnaz S, et al. Subfertile women; Frequency of factors leading to tubal blockage Evaluated by laparoscopy. Professional Med J 2017;24. 
21. Ikechebelu JI, Eleje GU, Okafor CD, Akintobi AO. Endometriosis Seen at Diagnostic Laparoscopy for Women with Infertility. J Gynecol Res Obstet 2015;1:6-9.

22. Alabi OC, Zowa PK, Onwumere UM. Incidence of endometriosis on laparoscopy in a Nigerian Hospital. Trop J Obstet Gynaecol 2013;30:S28.

23. Dubbewar A, Nath SK. Observational study of HSG with laparoscopic correlation in infertility patients. Int J Reprod Contracept Obstet Gynecol 2018;7:1903-7.

24. Eskenazi B, Warner ML. Epidemiology of Endometriosis. Obstet Gynaecol Clin North Am 1997;24:235-58.

25. Mahran A, Abdelraheim AR, Eissa A, Gadelrab M. Does laparoscopy still has a role in modern fertility practice? Int J Reprod Biomed 2017;15.

26. Tanaka A, Tanaka I, Yamaguchi T, et al. Development of a new tubal recanalization method using the combination of hystero- scope and laparoscope in the treatment of obstructed fallopian tubes. Gynaecol Minimal Invasive Ther 2017;6:226-7.

27. Takeda M, Miyatake T, Tanaka A, et al. Rare hydrosalpinx in a sexually inactive adolescent successfully treated with laparoscopy. Gynecol Minimal Invas Ther 2017;6:76-8.

28. Zepiridis LI, Grimbizis GF, Tarlatzis BC. Infertility and uterine fibroids. Best Pract Res Clin Obstet Gynaecol 2016;34:66-73.

29. Practice Committee of the American Society for Reproductive Medicine. Removal of myomas in asymptomatic patients to improve fertility and/or reduce miscarriage rate: a guideline. Fertil Steril 2017;108:416-25.

30. Baikpour M, Moawad NS, Eaton JS, Hurd WW. An $8 \mathrm{~cm}$ Subserosal Fibroid in a Patient with Unexplained Infertility and Pain. In Uterine Fibroids 2018 (pp. 107-123). Springer, Cham. 